\title{
RESEÑA/REPORT
}

\section{LA CARA INTERNA DE LA COMUNICACIÓN EN LA EMPRESA David Caldevilla Domínguez Visión Libros, Madrid 2010}

Juan Enrique Gonzálvez Vallés²: Universidad Camilo José Cela (Madrid). España. juanen2012@gmail.com

En cada libro dedicado a la comunicación empresarial se descubre un muy alto interés por parte del profesional en lo que nosotros conocemos como la Gestión Integral. Una disciplina que no se podía obviar de ninguna manera en esta última publicación de David Caldevilla, La Cara Interna de la Comunicación en la Empresa, donde ubicamos de forma totalmente clara y concisamente reflejo en su interior, de las múltiples experiencias amasadas por el investigador dentro del paradigma mercantil.

En este libro el autor nos propones sumergimos en la dinámica cotidiana de la empresa centrándonos más en los aspectos comunicativos y tecnológicos, así como las dinámicas interactivas provenientes de las relaciones humanas centrándose con especial cuidado en la dirección de comunicación y el Corporate, con especial precisión.

En el transcurso de estas páginas, es admirable la focalización temática recalada en los trabajos de dirección, nexo conceptual hacia los próximos epígrafes que desembocan en uno de los pilares básicos de la investigación de Caldevilla: los grupos de presión, o lobbies.

\footnotetext{
${ }^{2}$ Autor correspondiente:

Juan Enrique Gonzálvez Vallés: Profesor de Marketing de la Universidad Camilo José Cela (Madrid). España.

Correo: juanen2012@gmail.com
} 
Como puente hacia el entendimiento de las materias y conceptos expresados dentro de esta publicación el autor se sirve de todos los trabajos realizados en su larga docencia con alumnos, a través de la defensa hipotética de campañas de imagen, algunas de ellas bastante brillantes. A través de ellas nos acercamos con cierta profundidad al mundo de las Relaciones Públicas sobre todo en la vertiente relacionada con el poder, vital para el devenir de una empresa, debido a los altos mecanismos de control que se están dando últimamente en muchísimos sectores. Por lo tanto la relación entre las corporaciones y los grupos de poder es un elemento básico en estas páginas.

A lo largo de todo este libro podremos sumergirnos en profundidad en las Relaciones Públicas y en algunas materias englobadas como el concepto de Responsabilidad Social Corporativa, importante en la relación entre la empresa y sus partes interactivas. Importantes también son las reflexiones sobre los códigos de conducta y los conceptos de reputación e imagen de empresa puesto que forman parte del complejo englobado por las relaciones sociales que presionas a la propia entidad empresarial, tanto de manera legal y jurídica como culturalmente, a través de la ética y los códigos deontológicos establecidos per se.

Importante también en el recorrido de este tratado de las Relaciones Públicas es la parte dedicada a la gestión de las crisis por parte de las directivas de los entes empresariales, y más ahora, que nuestro país se encuentra en un proceso de fagocitación de recursos económicos que están afectando muy gravemente al sector económico y que están llevando al cierre de muchas empresas. Importante sobre todo es la búsqueda de soluciones y el amplio abanico que se nos desvela el autor, gracias a sus múltiples investigaciones dentro de este campo.

No hay que olvidar que todo esfuerzo docente conlleva una sencillez en los postulaos y unos preceptos de transparencia que, en el caso del presente libro, se cumplen con rigor propio de quien lleva dieciocho años en las aulas complutenses.

En definitiva, un ejemplar necesario para la biblioteca práctica de cada empresario y un muy buen manual de estudio de gestión de las Relaciones Públicas para un alumno. 